\title{
Characteristics and performance of village animal health workers and veterinary assistants in northern Malawi
}

\author{
$\mathrm{K} \mathrm{Hüttner}^{\mathrm{a}^{*}}, \mathrm{~K}^{\text {Leidl }}{ }^{\mathrm{b}}$, F B D Jere ${ }^{\mathrm{b}}$ and D U Pfeiffer ${ }^{\mathrm{c}}$
}

\begin{abstract}
Fourty-two village animal health workers called keymen (KM) and 84 veterinary assistants (VA) involved in a Basic Animal Health Service (BAHS) Programme in northern Malawi were interviewed during 1998. The general characteristics and perceptions of both groups were analysed using uni- and multivariate techniques. Detailed sales and treatment patterns of sixKM and 12VA wereevaluated for the period September 1996 to August 1997. Results indicated an overall job-satisfaction for $82 \%$ of KM and $83 \%$ of VA. Estimated weekly involvement in livestock service delivery, particularly of KM, was 3.7 days on average. Total annual drug sales of KM and VA between 1996 and 1997 on average were equivalent to US\$124 and US\$218 respectively. Most livestock remedies were issued for treatment of calves, followed by adult cattle, chickens and small ruminants. The changes suggested by VA and KM in order to improve field performance focused on regular refresher training by the BAHS programme.
\end{abstract}

Key words: community-based livestock services, Malawi, village animal health workers. Hüttner K, Leidl K, Jere F B D, Pfeiffer D U Characteristics and performance of village animal health workers and veterinary assistants in northern $\mathrm{M}$ alawi. Journal of the South African Veterinary Association (2000) 71(3): 160-165 (En.). EpiCentre, Massey University, Palmerston North, New Zealand.

\section{INTRODUCTION}

Numerous primary animal health programmes have been initiated during the past 20 years in developing countries all over the world $d^{1-5,10,14,16}$. The involvement of trained farmers (village animal health workers, laymen, keymen, bare foot-vets) is one of the key-elements in almost every programme in order to develop practicable approaches for livestock health service delivery in remote areas. Despite the significance of this group, only a few studies have been published that describe the characteristics and experiences of these people in detail $^{11,15,17}$.

The Basic Animal Health Service (BAHS) Programme in northern Malawi was launched in the late 1980 s by the Department of Veterinary Services, assisted by the German Agency for Technical Cooperation (GTZ), to provide a regional service to livestock owners. Self-help, demand-driven strategies and consequent cost-recovery are essential components of the programme's philosophy. All administrative matters are managed

aEpiCentre, Massey University, Palmerston North, New Zealand.

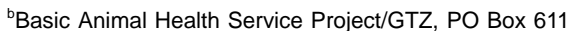
Mzuzu, Malawi.

${ }^{\mathrm{c}}$ Royal Veterinary College, London, United Kingdom.

*Author for correspondence: e-mail: k.huttner@massey.ac.nz Received: November 1999. Accepted: July 2000. through afarmers' association (Foundation for the Improvement of Animal Health, which is registered as a legal entity under the laws of Malawi. More details about the set-up of the BAHS scheme can be obtained from Leidl et al. ${ }^{13}$. At present the BAHS programme operates within an area of $27000 \mathrm{~km}^{2}$. The focal point of the programme is part-privatisation of Government field veterinary services through establishing a Drug Revolving Fund (DRF), and deployment of trained farmers, appointed by their community, as village-keymen (KM). Figure 1 illustrates the DRF drug and money flow as part of extension pictorials produced by the BAHS programme. The trainees have to meet certain prerequisites before being accepted by both the respective village livestock group and the BAHS team. These criteria include literacy, experience with livestock keeping, ageand reliability. After an initial 4-day training, KM are supplied with a kit (drug box), which allows them to treat village livestock and provide general advice on health and husbandry in their home area. Veterinary assistants (VA), who are Government employees, take part in the programme by handling a drug box that includes injectable drugs, which distinguishes it from the KM's box. In addition, VA provide backup and supervision to $K M$ in their area.

The BAHS programme currently offers a range of 40 different drugs and additional items such as sprayers, ropes, calculators and tubes. Most of the drugs are tailored to meet the needs of the traditional farming sector, with emphasis on disease prevention. Many of them have been re-packaged into smaller and thus affordable quantities. The greatest demand is for dewormer-drenches (for prevention of helminthiasis caused by Toxocara spp. and Strongyloides spp. in young stock), pour-on formulae against ecto-parasites (mainly to prevent East Coast fever in cattle), and long-acting oxytetracycline for curative purposes ${ }^{9}$.

The aim of the current study was to describe characteristics, perceptions and performance of KM and VA involved in the BAHS scheme. The identification of factors limiting the effectiveness of the field service and motivation of field workers was considered to be important information that was required to develop strategies for continued enhancement and adaptation of the programmeto meet the needs of the target population. The study is part of a comprehensive impact assessment of the BAHS programme?

\section{MATERIALS AND METHODS}

\section{Selection of VA and KM and data collection}

A total of 149 VA and KM were operating drug boxes from June 1998 in the study area, which covers about $60 \%$ of the entire area of the BAHS operation. Of these, $42 \mathrm{KM}$ and $84 \mathrm{VA}$ with a minimum of 12 months' involvement in the BAHS programme were included in the study. The survey questionnaire used for structured interviews was pre-tested with 3KM and 4VA, and adjusted accordingly. Major sections included social and farm characteristics, BAHS workload, job satisfaction, difficulties experienced while performing BAHS duties, and selfperception. Three members of the BAHS team conducted the structured interviews between July and December 1998, each of which lasted about 30 minutes. 
For detailed analysis of drug sales and treatment patterns, $6 \mathrm{KM}$ and $12 \mathrm{VA}$ were evaluated. The selection was based on completeness of annual accounting and prescription form data entries for the period of September 1996 to August 1997. Whilethese results are not representative of the entire study population, they suffice to provide a general indication of the performance of KM and VA.

\section{Data analysis}

Data were stored using Microsoft Access 97 (Microsoft Corporation, Redmond, USA). Global positioning system receivers were used to determine the precise locations of KM houses and VA stations within the study area. Maps were produced using the geographical information system software Arcview for Windows version 3.1 (ESRI Inc., Redlands, USA). Statistical analyses were performed using NCSS 2000 (NCSS Statistical Software, Kaysville, Utah, USA) and STATISTICA/W version 5.1 (StatSoft, Tulsa, Oklahoma, USA). Multiple corre spondence analysis (MCA) was used to explore the data for relationships between categorical variables contained in simple 2-way or multi-way tables. The goal was to represent the entries in each table as distances between individual rows and/or columns in a low-dimensional graphical space. Another way of looking at MCA is to consider it as a method for decomposing the overall $\chi^{2}$-statistic (or inertia $=\chi^{2}$ (total $\mathrm{n}$ ). What isimportant are thedistances of thepoints in the2-dimensional display. Row pointsthat are closeto each other indicate a pattern of relative frequencies across the columns. Adding supplementary column points to the de sign matrix (in our case the KM/VA status), permits the equivalent of a multiple regression for categorical variables to be performed. The summary statistics (total inertia) provides an indication of how well one can explain the KMNA status as a function of the other variables in the design. The column points in the final coordinate system should provide an indication of thenature (e.g. direction) of the relationships between the columns in the design matrix and the supplementary column points, indicating BAHS user-status ${ }^{6}$.

\section{RESULTS}

\section{Locations of drug box holders}

The study area covers approximately $18000 \mathrm{~km}^{2}$ of which about $7000 \mathrm{~km}^{2}$ are forest reserves, national parks or game reserves. The KMs houses and stations of VAs involved in the BAHS programme are shown in Fig. 2. The map illustrates

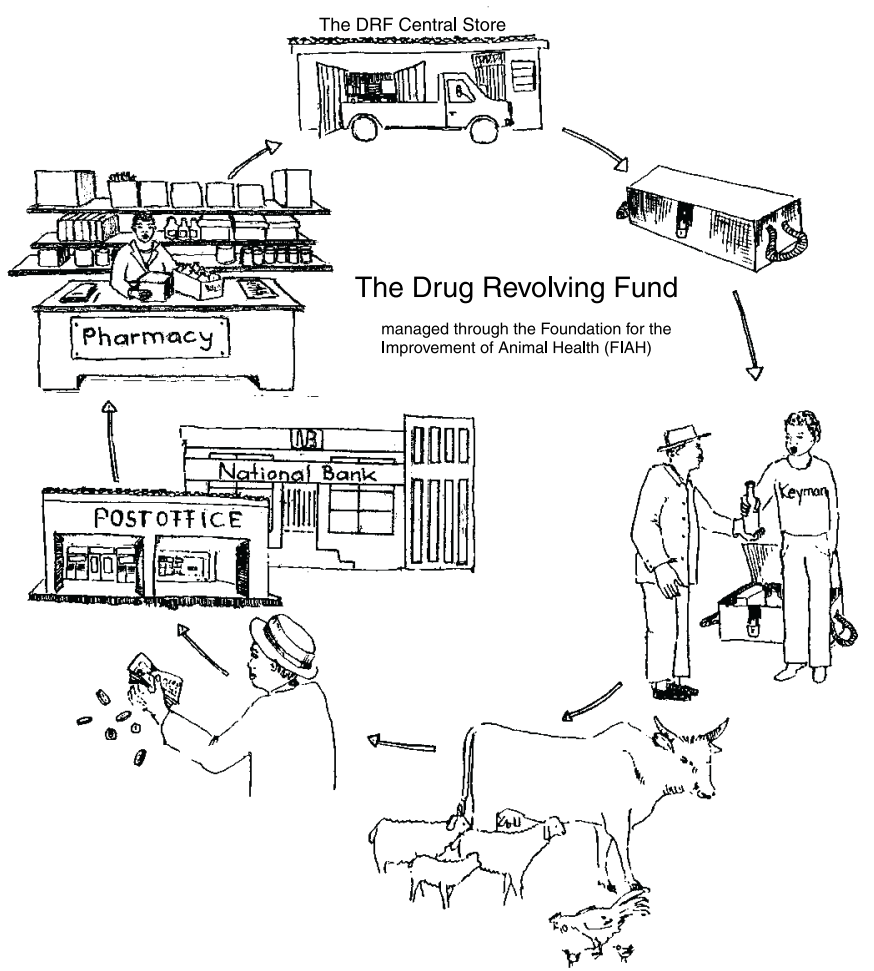

Fig. 1: The drug and money flow of the Drug Revolving Fund, the core piece of the BAHS programme (pictorial as part of BAHS extension material).

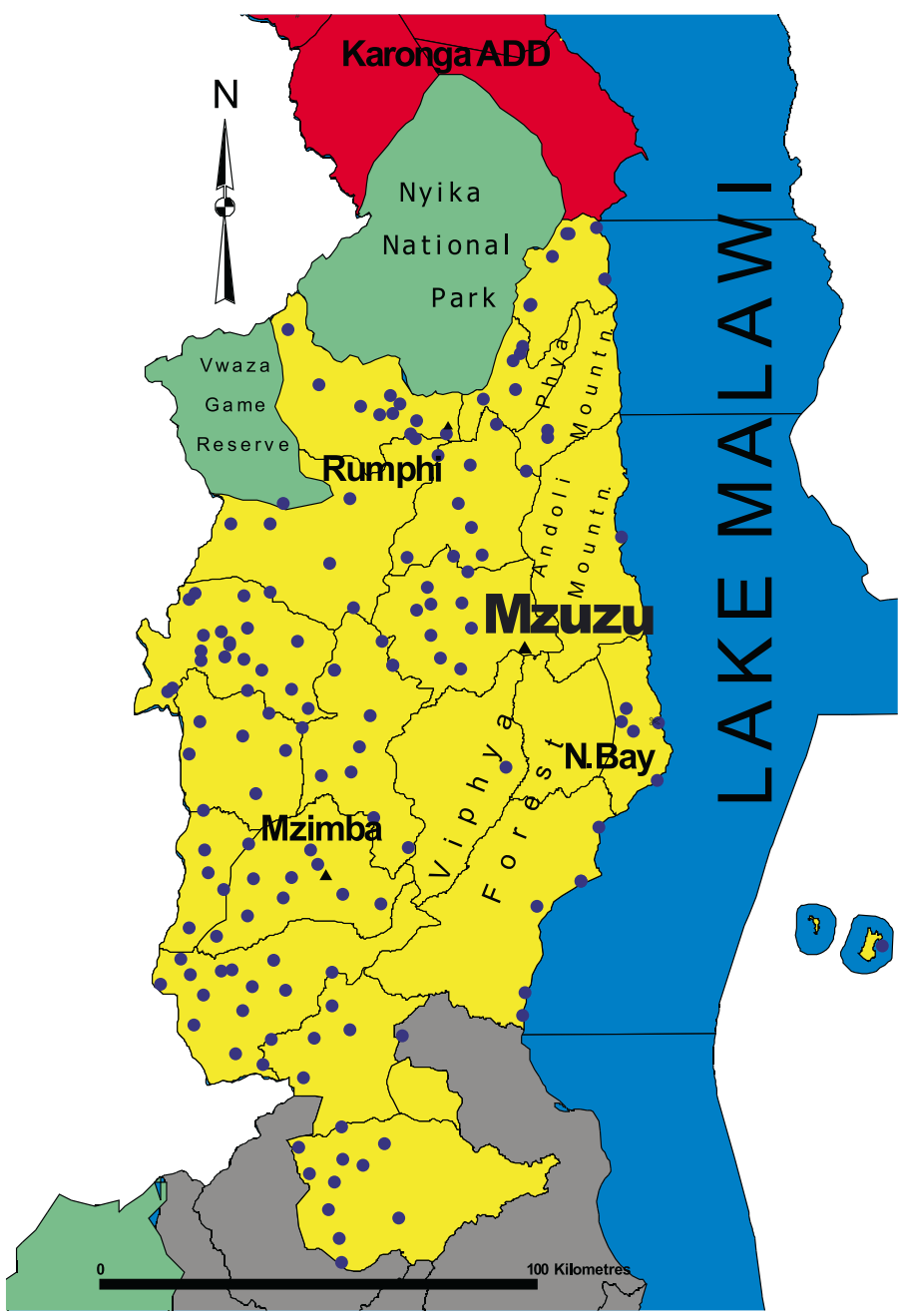

Fig. 2: Distribution of all drug boxes ( $\bullet$ ) within Mzuzu Agricultural Development Division as of August $1999(n=149)$. 
Table 1: Comparison of VA and KM characteristics and work-related issues.

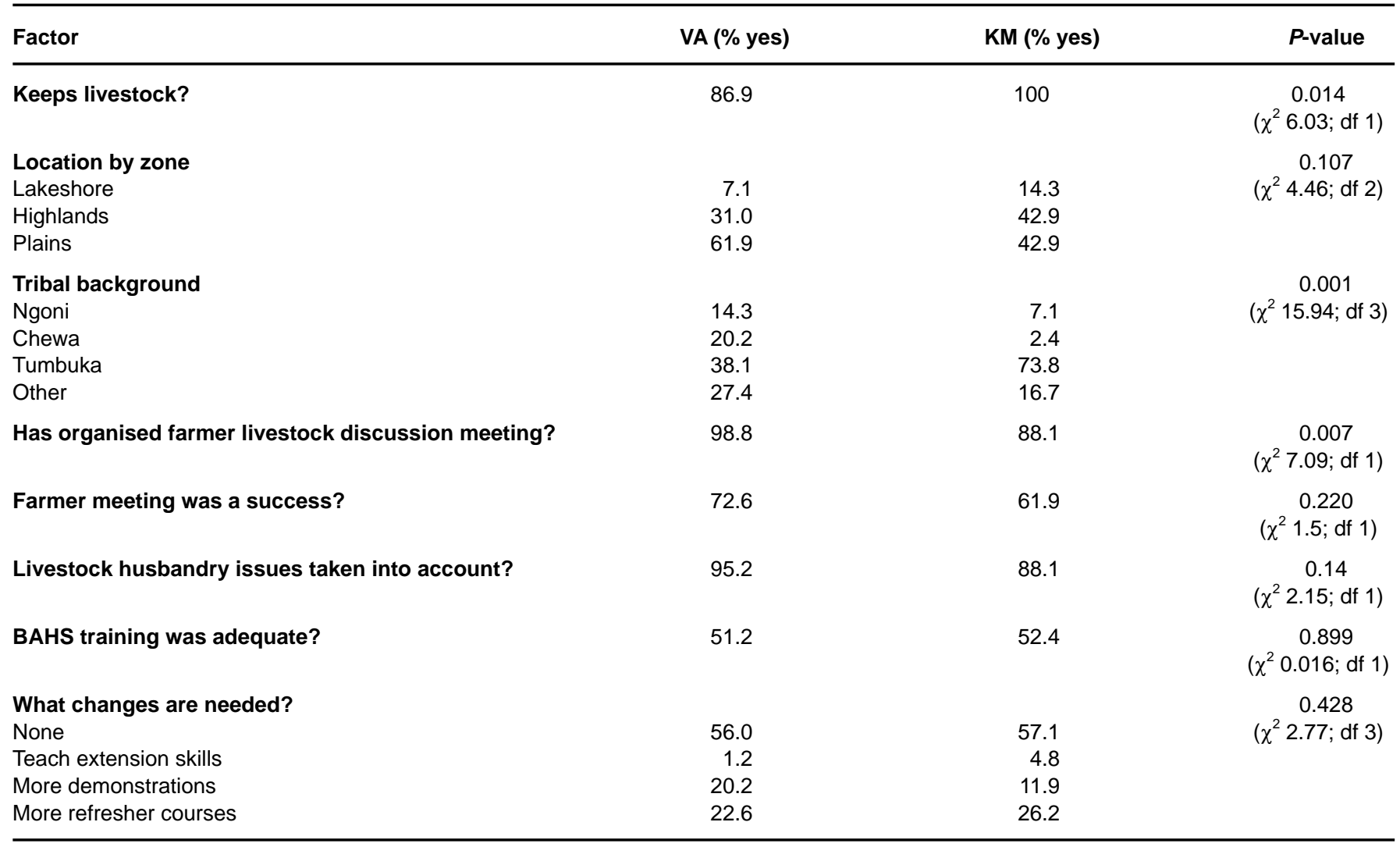

the extensive coverage of the BAHS programme throughout the study area (Mzuzu Agricultural Development Division).

\section{General description of VA and KM}

All KM and VA were male. The average age of VA and KM was 37.4 years (SD 8.7) and 42.6 (SD 10.1), respectively. VA estimated their weekly BAHS workload to be 4.1 days (SD 1.7), which is higher than the estimate provided by the KM (3.7 days, SD 1.8). On average, VA had received their drug box 2.8 years ago (SD 1.37) compared with 3.4 yearsfor KM (SD 1.83). Table 1 is a summary of additional keycharacteristics of both groups. More KM than VA own livestock themselves. Relatively moreVA than KM werebased in the plains area. The population in the study area includes people from 14 different tribes, with most belonging to the Tumbuka. There is greater variation in the tribal origin of KM than of VA. The Tumbuka tribe appeared to be underrepresented in the VA-group.

More than half of both groups were satisfied with the initial training they had received through the BAHS scheme. Fourty-four percent of VA and $43 \%$ of KM suggested some changes, with most of these groups requesting regular refresher courses and practical demonstrations. Almost every VA and $88 \%$ of KM had organised livestock farmer meetings in villages. Fewer KM than VA were satisfied with the outcome of the meeting(s) they conducted. Both groupswerehighly likely to include advice on livestock husbandry and management in addition to treatments as part of their field services.

\section{Annual drug sales and treatment regime}

Table2 providesasummary of drug use, which reflects patterns across species summarised for the 12 VA and $6 \mathrm{KM}$ drug box locationsselected for a detailed survey. Most prescriptions were issued for treatment of calves, followed by adult cattle, chickens and small ruminants. A relatively small number of pig prescriptions were issued. The VA at Kachereappeared to be the most active person, followed by the KM in Mdolo, based on total number of visits. The average annual number of farm visits by the selected KM was 81.3 (SD 32.7) involving 42.2 (SD 23.6) farms, compared to 78.4 visits (SD 40.4) and 33.6 (SD 31.5) farms for VA. Comparing medians statistically did not show any significant differences between KM and VA.

Table 3 provides a summary of drug sales per selected drug box location. The calculation is restricted to the 4 drugs in greatest demand. There were no significant differences between drug sales by $K M$ and VA. Since KM are not entitled to use injectables, a statistical comparison was not performed for long-acting oxytetracycline (LA-OTC). The average drug sales turnover for VA of *MK3271.5 (US\$ 218) is almost twice as high as that for KM with *MK1859.3 (US\$ 124), which is significantly different.

\section{Job satisfaction and self-perception}

Eighty-two percent of $\mathrm{KM}$ and $83 \%$ of VA stated that they enjoyed their job. When asked for reasons, $59 \%$ of KM and $55 \%$ of VA mentioned drug availability after years of ineffective field services. Twenty fivepercent of $\mathrm{KM}$ and $31 \%$ of VA felt they had gained knowledge about livestock production. Almost half of all KM (47\%) and a third of VA (34\%) reported an increase in self-esteem. All the KM and $96 \%$ of VA indicated that they were satisfied with the job because farmers showed their appreciation. Figure 3 providesagraphical summary of these findings based on multiple correspondence analysis. The model explains $44 \%$ of inertiausing 2 dimensions. The 1 st dimension mainly relates to BAHS programme aspects, whereas the 2nd separates the study population according to their relationship with farmers. The overall job satisfaction is clearly reflected by the closeness of a range of column points to both, KM and VA. These are statements such as 'I like my job as a

*1 US\$ = 15 MK (Malawi kwacha) in December 1996. 
Table 2: Annual number of farm visits and total treatments by KM/VA per species between September 1996 and August 1997 (Kruskal-Wallis 1 -way ANOVA to compare between KM and VA groups, $P<.05$ ).

\begin{tabular}{|c|c|c|c|c|c|c|c|}
\hline \multirow[b]{2}{*}{ Location } & \multirow[b]{2}{*}{$\begin{array}{l}\text { Total number } \\
\text { of farms }\end{array}$} & \multirow[b]{2}{*}{$\begin{array}{l}\text { Number } \\
\text { of visits }\end{array}$} & \multicolumn{5}{|c|}{ Number animals (number of farms involved) } \\
\hline & & & $\begin{array}{c}\text { Calves } \\
(<12 \text { months })\end{array}$ & Adult cattle & Sheep/goats & Chickens & Pigs \\
\hline \multicolumn{8}{|l|}{ KM-locations } \\
\hline Kavululanga & 57 & 80 & $35(25)$ & $36(27)$ & $1(1)$ & $861(29)$ & $1(1)$ \\
\hline Madede & 14 & 90 & $65(6)$ & $26(4)$ & $48(1)$ & $1584(5)$ & $3(1)$ \\
\hline Matete & 23 & 41 & $57(22)$ & $46(18)$ & $2(1)$ & $171(9)$ & $1(1)$ \\
\hline Mdolo & 75 & 132 & $91(36)$ & $55(21)$ & 99 (33) & 732 19) & $18(8)$ \\
\hline Visenthe & 55 & 94 & $49(27)$ & $44(29)$ & $15(2)$ & $472(21)$ & $23(8)$ \\
\hline Yakuwata & 31 & 51 & $23(14)$ & $34(16)$ & $2(2)$ & $1455(8)$ & 0 \\
\hline $\mathrm{KM}$ averages of species (SD) & $\begin{array}{c}42.2 \\
(23.6)\end{array}$ & $\begin{array}{c}81.3 \\
(32.7)\end{array}$ & $\begin{array}{c}53.3 \\
(23.8)\end{array}$ & $\begin{array}{c}40.2 \\
(10.2)\end{array}$ & $\begin{array}{c}27.8 \\
(39.2)\end{array}$ & $\begin{array}{c}879.2 \\
(550.9)\end{array}$ & $\begin{array}{c}7.7 \\
(10.1)\end{array}$ \\
\hline \multicolumn{8}{|l|}{ VA-locations } \\
\hline Chitanga & 28 & 78 & $35(9)$ & $56(9)$ & $42(7)$ & $630(8)$ & $78(8)$ \\
\hline Chitimba & 17 & 47 & $28(11)$ & $17(8)$ & $31(3)$ & $480(17)$ & $6(1)$ \\
\hline Jata & 44 & 66 & $111(40)$ & $57(28)$ & $6(3)$ & $219(10)$ & $14(1)$ \\
\hline Kachere & 114 & 187 & $167(62)$ & $116(18)$ & $30(4)$ & $3909(68)$ & $1(1)$ \\
\hline Kampupu & 63 & 97 & $71(23)$ & $54(32)$ & $19(6)$ & $185(9)$ & $6(1)$ \\
\hline Kapopo & 26 & 39 & $55(14)$ & $37(13)$ & 0 & $98(7)$ & $1(1)$ \\
\hline Katumbi & 38 & 58 & 45 (17) & 45 (11) & $4(1)$ & 2115 (13) & $32(10)$ \\
\hline Luzi & 41 & 70 & $72(29)$ & $44(14)$ & $8(3)$ & 288 (12) & $23(7)$ \\
\hline Magido & 17 & 68 & $238(13)$ & $10(5)$ & $3(1)$ & $261(8)$ & 0 \\
\hline Mzikubola & 9 & 72 & $44(5)$ & $15(3)$ & $54(3)$ & $937(4)$ & $5(1)$ \\
\hline Ng'onga & 27 & 44 & $38(15)$ & $24(14)$ & $36(7)$ & $41(2)$ & $4(1)$ \\
\hline Vibangalala & 39 & 115 & $200(45)$ & $69(36)$ & $32(5)$ & $1280(21)$ & $7(2)$ \\
\hline VA averages of species (SD) & $\begin{array}{c}33.6 \\
(31.5)\end{array}$ & $\begin{array}{c}78.4 \\
(40.4)\end{array}$ & $\begin{array}{l}92 \\
(71.3)\end{array}$ & $\begin{array}{c}45.3 \\
(29.2)\end{array}$ & $\begin{array}{c}22.1 \\
(17.8)\end{array}$ & $\begin{array}{c}870.3 \\
(1130.3)\end{array}$ & $\begin{array}{c}14.8 \\
(22.1)\end{array}$ \\
\hline$P$-value & & 0.57 & 0.37 & 0.74 & 0.64 & 0.45 & 0.35 \\
\hline
\end{tabular}

KMNA', 'I feel supported by the BAHS team', 'Farmers do show their appreciation for my efforts' and 'I enjoy talking to farmers on BAHS issues'. Negative feedback from farmers or not feeling sup- ported, were unlikely outcomes for both groups.

One issue was perceived very differently by KM and VA. VA experience difficulties significantly more frequently when dealing with livestock farmers (73\%), as compared with KM (43\%) ( $\mathrm{P}=$ $0.001)$. When asked to specify those difficulties, the following was disclosed: $40 \%$ of the 126 interviewees mentioned a

Table 3: Sales of most wanted BAHS drugs per selected location between September 1996 and August 1997 (using Kruskal-Wallis 1-way ANOVA to indicate statistically significant differences between KM and VA, $P<0.05$ ).

\begin{tabular}{|c|c|c|c|c|c|}
\hline Location & Dewormer 1 & Dewormer 2 & Pour-on (sum in cc) & LA-OTC (sum in ml) & Total in $\mathrm{MK}^{*}$ \\
\hline \multicolumn{6}{|l|}{ KM-locations } \\
\hline KM Kavululanga & 34 & 32 & 51 & 0 & 1619.80 \\
\hline KM Madede & 40 & 33 & 262 & 0 & 1978.10 \\
\hline KM Matete & 31 & 39 & 815 & 0 & 1828.00 \\
\hline KM Mdolo & 47 & 61 & 525 & 0 & 2638.70 \\
\hline KM Visenthe & 29 & 67 & 124 & 0 & 2176.40 \\
\hline KM Yakuwata & 11 & 25 & 161 & 0 & 915.00 \\
\hline KM averages (SD) & $32.0(12.2)$ & $42.8(17.1)$ & $323(292.0)$ & 0 & $1859.33(578.3)$ \\
\hline \multicolumn{6}{|l|}{ VA-Iocations } \\
\hline VA Chitanga & 42 & 43 & 183 & 150 & 3234.20 \\
\hline VA Chitimba & 22 & 1 & 292 & 99 & 1986.20 \\
\hline VA Jata & 48 & 37 & 331 & 363 & 3874.30 \\
\hline VA Kachere & 97 & 54 & 1731 & 296 & 5679.50 \\
\hline VA Kampupu & 12 & 35 & 1242 & 353 & 4079.95 \\
\hline VA Kapopo & 15 & 23 & 72 & 236 & 2214.50 \\
\hline VA Katumbi & 33 & 19 & 185 & 121 & 2883.60 \\
\hline VA Luzi & 29 & 15 & 637 & 312 & 2865.98 \\
\hline VA Magido & 57 & 26 & 287 & 398 & 3072.10 \\
\hline VA Mzikubola & 17 & 34 & 253 & 267 & 2468.00 \\
\hline VA Ng'onga & 11 & 7 & 383 & 336 & $2,221.50$ \\
\hline VA Vibangalala & 63 & 80 & 102 & 470 & 4677.70 \\
\hline VA averages (SD) & $37.2(25.8)$ & $31.2(21.5)$ & $474.8(505.5)$ & $283.4(114.2)$ & $3271.46(1114.6)$ \\
\hline$P$-value & 0.85 & 0.26 & 0.45 & - & 0.003 \\
\hline
\end{tabular}

*1 US\$ = 15 MK (Malawi kwacha) in December 1996. 


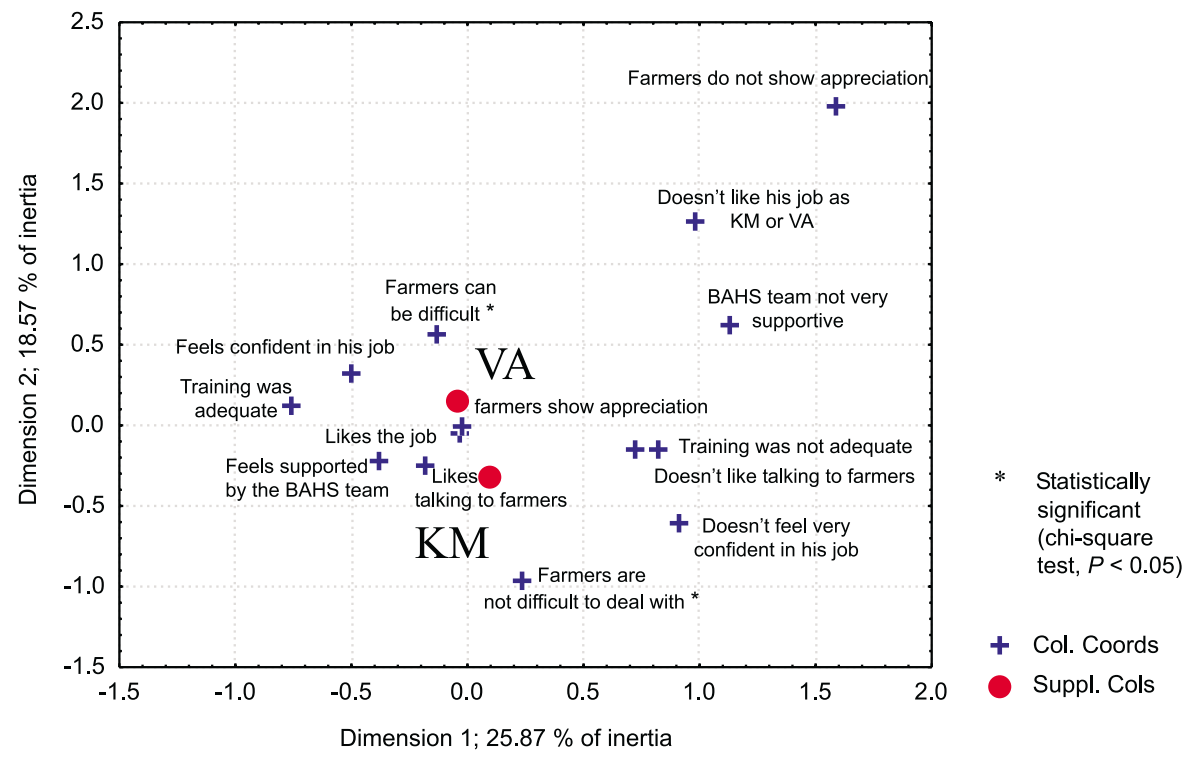

Fig. 3: Results of multiple correspondence analysis of job satisfaction and self-perception. The indicators of job satisfaction and self-perception are displayed as column coordinates (Col. Coords) while the KM/VA-status is added as supplementary column points (Suppl. Cols). Chi-square analysis results for cross-tabulated data are included.

misunderstanding of the BAHS concept by farmers, namely the principle of pre vention rather than cure, issues of self-help, lack of cooperation by the village livestock group and treatments on a cash rather than a loan basis. Thirty percent of all VA and KM stated that there are communication problems (getting farmers together, inability to explain certain technical issues, cultural/tribal barriers,) and $17 \%$ said that farmers had problems in accepting the current drug and treatment prices.

\section{DISCUSSION}

Thefact that the communitiestended to select comparatively older farmers as KM is part of a culture of respecting elders in their communities. Meemark ${ }^{15}$ reported the average age of keymen in northeast Thailand to be 39 years, almost identical to the situation in Malawi. The BAHS programme team advises against selection of KM of an advanced age (e.g., 4KM are older than 60 years) because of the physical demands of service delivery.

An estimated BAHS weekly workload of 3.7 days for KM as compared to 4.2 for $\mathrm{VA}$ is remarkably high, considering the additional commitments of KM as farmers themselves. Although $\mathrm{KM}$ as well as VA are provided with a bicycle as part of the initial drug-box delivery, it is known that distances and absence of roads can result in every farm visit becoming a tire some and time-consuming job. Woods ${ }^{18}$ found proximity to the clientele to be a crucial determinant of the quality and frequency of livestock services for the performance of veterinary technicians in Zimbabwe. Apart from farm visits, activi- ties of KM and VA include bookkeeping, group-meetingsand cash accounting and transfer, which involves hand-over of cash to the treasurer of the village livestock group, but also stock-taking whenever requested by either the BAHS team or the village group. For a basic animal health project in northeast Thailand, KM bookkeeping was limited to filling in forms for drugs received/drugs sold ${ }^{15}$, whereas it is much more demanding in the case of the BAHS programme in Malawi. The differences in KM/VA locations according to ecological zones (Table 1), including distances to their BAHS clientele have been evaluated recently ${ }^{8}$.

The majority of both groupsenjoy their role in livestock service delivery. Almost all of the VA and $88 \%$ of KM organized meetingsto promotetheprogramme, and about $2 / 3$ of both groupsthought that they had performed this task successfully. The BAHS training, however, was not perceived to beadequateby the KM and VA. Their first suggestion was regular refresher courses, followed by moreapplied demonstrations and sessions on development of extension skills as shown in Table 1. It should be noted that the BAHS programme conducted regular refresher courses until 1997, and then committed VA and their supervisors to play an active part in KM training and supervision. This has apparently not worked well. One of the reasons is certainly due to changes (reduction) in the number of staff involved with the BAHS team.

Jones $^{11}$ referred to an initial 2-week training for village animal health workers in southern Sudan, followed by arefresher course after another 6-12 months. Apart from the initial training of 4 days mentioned earlier, the BAHS team places much emphasis on ongoing supervision of $\mathrm{KM}$, in particular by veterinary field staff. The regular BAHS drug delivery tours provide an additional opportunity for supervision and discussion, as does the annual stock-taking event attended by each livestock group.

In terms of service delivery, cattle as the economically most valued animals receive most of the attention. Pigs receive the least input in terms of drugs. This is not surprising, because efforts by BAHS to promote enhanced pig production in villages so far have been rather modest. It is noticeable that $\mathrm{KM}$ as lay practitioners on average visited morefarms more often than VA. There are, however, no significant differences between KM and VA with regard to average visit numbers, drug sales or treatments performed. KM apparently spent more visits on fewer animals when compared with VA, while VA at the same time sold more drugs. The latter figure is increased by sales of antibiotics and other relatively expensive injectables through VA. Although VA on average had almost twice the turnover of $\mathrm{KM}$, the large data variation and small sample size makes it difficult to obtain a clear picture of the situation. The fact that the number of VA and KM included in this calculation is not representative of all drug-box holders may be relevant in this context.

Seventy-threepercent of VA and $43 \%$ of KM said that they sometimes had problems when dealing with farmers. VA and KM attributed this to inability to attract sufficient farmers on one hand and poor understanding of the BAHS concept by farmers on the other. Government field staff in general have a reputation of passivity and inefficiency, which is inherited froma history of pure state services ${ }^{12}$. It is also possible that tribal issues influence farmers' interest in the scheme. This is supported by the fact that al most $2 / 3$ of VA do not belong to the Tumbuka, who predominate in the study area (Table 1). This factor should be taken into consideration during future phases of the BAHS programme, but remains to be further investigated.

When interpreting the responses that VA and KM provided in this survey, a tendency to give positive rather than negative information in relation to the programme must be taken into account, asVA and KM themselves receivea financial benefit from BAHS. Subjectivity and potential response bias do not invalidate the conclusions of the analysis, which provides an important summary of 
VA/KM perceptions in relation to BAHS.

As illustrated in Fig. 3, the overall job satisfaction of VA and KM involved in the BAHS programme is the most striking pattern that emerged from this study. It resulted to a significant extent from the encouraging responsethey received from their clientele. The feeling of support by theBAHSteam and enjoyment from talking to farmers was common in both groups. This was closely related to personal perceptions such as increased selfesteem and positivelearning experiences. It is clear that for community-based live stock programmes to be successful in the short-term and sustainable in the long term, villageanimal workersmust receive a perceived benefit from the programme, which need not necessarily to be measurable on purely economic grounds.

\section{ACKNOWLEDGEMENTS}

Conducting this study was not just a component of aBAHSimpact assessment, it was also part of the BAHS team approach, and thus provided much enjoyment for all parties involved. We wish to thank all keymen and veterinary assistantsaswell astheir supervisors involved in this study for their cooperation.

\section{REFERENCES}

1. Abdel-Messieh F 1996 Basic animal health services in the Kingdom of Lesotho. In Zimmermann W, Pfeiffer D U and Zessin K $\mathrm{H}$ (eds) Primary animal health activities in southern A frica. Proceedings of an International Seminar, M zuzu, M alawi, 26 February - 8 March 1996. German Foundation for International Development, Feldafing, Germany: 324-331

2. Akabwai D M O 1992 Paravet training among Turkana pastoralists of Kenya. In Daniels P W, Holden S, Lewin E and
Dadi S (eds) Livestock services for smallholder: a critical evaluation of the delivery of animal health and production services to the small-scale farmers in the developing world. International Seminar Proceedings, Yogyakarta, Indonesia, 15-21 November 1992: 232-234

3. Arambulo P V, Aleta I R, Vallenas A 1986 Community participation in veterinary public health and animal health in the Caribbean - results of a preliminary survey. International Journal of Zoonoses 13, 162-173

4. Baptist $R$, Rajasmina A, Rakotoarimanana D, Rasambainarivo J H 1994 Private vets for the rural areas of Madagascar. The Kenya Veterinarian 18: 510-512

5. Grandin B, Thampy R, Young J 1991 Village animal healthcare: a community-based approach to livestock development in Kenya. Intermediate Technology Publications, London

6. Greenacre M 1992 Correspondence analysis in medical research. Statistical methods in medical research I: 97-117

7. Hüttner K, Leidl K, Jere F B D, Pfeiffer D U 1998Target group orientation of a basic animal health service program - first results of an impact assessment in northern Malawi. In Proceedings of the 9th International Conference of the A ssociation of Institutions of Tropical Veterinary M edicine (AITVM ), H arare, Zimbabwe, 14-18 September 1998: 296-309

8. Hüttner K, Pfeiffer D U, Leidl K, Jere F B D, Kasambara, D (in press) Farm and personal characteristics of the clientele of a community-based animal health service programme in northern Malawi. Tropical Animal $\mathrm{H}$ ealth and Production

9. Jere F B D 1997 Basic animal health service in Northern Malawi. In Zimmermann W, Pfeiffer D U, Zessin K H (eds) Primary animal health activities in southern Africa. Proceedings of an International Seminar, M zuzu, M alawi, 26 February - 8 March 1996. German Foundation for International Development, Feldafing, Germany: 211-234

10. Johnson P J, Chahuares C 1990 Training Anyamara veterinary technicians in the southern Peruvian Andes. Convergence 23: 14-22

11. Jones B A, Deemer B, Leyland T J, Mogga W, Sterm E 1998 Community-based animal health services in Southern Sudan - the experience and future. In Proceedings of the 9th International Conference of the Association of Institutions of Tropical Veterinary M edicine (AITVM ), H arare, Zimbabwe, 14-18 September 1998: 107-133

12. Lechner H L G, Böhm A 1990Assessment of the veterinary field service of Mzuzu A.D.D. in 1988/89 and recommendations for an improvement of efficiency. Mzuzu, Malawi, $162 \mathrm{pp}$.

13. Leidl K, Jere F, Wanda G, Hüttner K, Stange M 1995 Establishment of a basic animal health service program in northern Malawi - dimensions of activities through field work prior to implementation. Proceedings of the 8th International Conference of Institutions of Tropical Veterinary M edicine, Berlin, Germany, 25-29 September 1995: 113

14. Loehr K F 1989The basic animal health service in north-east Thailand - the principle of the service. In Proceedings of an International Seminar on Animal $\mathrm{H}$ ealth and Production Services for Village Livestoc, Khon Kaen, Thailandk, 2-9 August 1989: 37-39

15. Meemark N 1988 The development and evaluation of a village-based parasite control program for swamp buffalo and cattle in northeast Thailand. Thesis, Massey University, Palmerston North, New Zealand.

16. Moktan D, Mitchelhill B K, Joshi Y R 1990 Villageanimal health workers in theKoshi Hills, Dhankuta District, Koshi Zone, Nepal. PCA Working Paper No. 4

17. Sulistiyo U, Wahyuni D, Leksmono C S1998 Village animal health workers in Minahasa District, North Sulawesi, Indonesia. In Proceedings of the 9th International Conference of the A ssociation of Institutions of Tropical Veterinary M edicine (AITVM), H arare, Zimbabwe, 14-18 September 1998: 340-349

18. WoodsP SA, Leonard D, Nielen M, Brand A 1998 The importance of proximity, transport and gender asfactors affecting the efficiency of veterinary service delivery in Zimbabwe. In Proceedings of the 9th International Conference of the A ssociation of Institutions of Tropical Veterinary M edicine(AITVM), $\mathrm{H}$ arare, Zimbabwe, 14-18 September 1998: 238-242 